\title{
O TRABALHO NO MUNDO CONTEMPORÂNEO: AS METAMORFOSES NO CONCEITO DE TRABALHO
}

\section{THE WORK IN THE CONTEMPORARY WORLD: THE METAMORPHOSES IN THE WORK CONCEPT}

\author{
${ }^{1}$ Prudêncio Hilário Serra Neto \\ ${ }^{2}$ Suzy Elizabeth Cavalcante Koury
}

\section{RESUMO}

O objeto do presente estudo é discutir o mundo do trabalho contemporâneo, sem ignorar as suas transformações históricas, na busca de respostas fora do eixo mercado/mercadoria. Pretende-se esboçar respostas a perguntas como: o trabalho sempre foi da forma como o conhecemos hoje? O trabalho existe para além do mercado? Como ficará o trabalho sem empregos? A fim de alcançar esse desiderato, buscaremos demonstrar, em um primeiro momento, as transformações do mundo do trabalho, desde a fase pré-capitalista, até o mundo contemporâneo, marcado pela globalização econômica e pela financeirização da riqueza. Enfrentar-se-ão alguns aspectos da chamada "crise" do emprego no mundo contemporâneo, decorrente dessas transformações, com a perda de hegemonia do trabalho face à sua frequente subdivisão e desqualificação. Por fim, discutir-se-ão possíveis caminhos, com destaque ao terceiro setor e à necessidade de cooperação e de reencontro do trabalho com a comunidade, desatrelando-se o valor humano das ideias de produtividade e de consumo, voltadas, unicamente, ao mercado. Espera-se que, suscitar o tema e estabelecer alguns pontos centrais, seja relevante para futuros aprofundamentos.

Palavras-chave: Trabalho, Mercado, Valor humano

\begin{abstract}
The purpose of this study is to discuss the world of contemporary work, without ignoring their historical transformations in the search for answers off-axis market / commodity. It is intended sketch answers to questions like: work has always been the way we know it today? The work exists beyond the market? How will the job without jobs? In order to achieve this aim, we will seek to demonstrate, at first, the transformation of the working world, from precapitalist stage, to the contemporary world, marked by economic globalization and financialization of wealth. Face will be some aspects of the "crisis" of employment in the contemporary world, due to these changes, with the loss of work hegemony face of their frequent subdivision and disqualification. Finally, they discuss will be possible ways, especially the third sector and the need for cooperation and reunion of working with the community, unleashing up the human value of the productivity of ideas and consumption, directed solely to the market. It is hoped that raising the issue and establish some key points relevant to future insights.
\end{abstract}

Keywords: Work, Market, Human value

\footnotetext{
${ }^{1}$ Mestrando em Direito, Políticas Públicas e Desenvolvimento Regional pelo Centro Universitário do Estado do Pará - CESUPA, Pará (Brasil). E-mail: prudencioneto@uol.com.br

${ }^{2}$ Doutora em Direito pela Universidade Federal de Minas Gerais - UFMG, Minas Gerais (Brasil). Professora do Centro Universitário do Estado do Pará - CESUPA, Pará (Brasil). E-mail: suzykoury@ gmail.com
} 


\section{INTRODUÇÃO}

De um modo geral, o campo de estudo do trabalho, sobretudo no âmbito jurídico, restringe-se à discussão das normas celetistas, em especial, a conceituação de empregado e de empregador, para efeito de reconhecimento de vínculo empregatício e os desdobramentos dessa relação.

Uma das premissas comumente destacada pela doutrina e pela jurisprudência é a hipossuficiência do empregado em relação ao empregador, tratada, contudo, sem maiores ponderações, nem aprofundamentos, repetida à exaustão, mas pouco compreendida. Afinal, como se falar em hipossuficiência se não se discutem, mais a fundo, as transformações históricas suportadas pelo mundo do trabalho?

De outro lado, o próprio papel do empregador e as suas demandas ao longo da história, também foi, gradualmente, obscurecido. Resta, atualmente, uma crença, bastante comum, que alça o empregador a uma condição de sujeito essencial e necessário, que deve ser protegido para que não fracasse e deixe de empreender, ainda que aspectos sociais possam ter que ser desconsiderados.

Em tal contexto de tensões, o mercado afirma-se como algo absolutamente necessário. Uma engrenagem que, ao funcionar mal, ou ao deixar de funcionar, representa o maior dos riscos. Não importa quanto o mundo mude ou em que velocidade realize as transformações, a ideia de mercado aparece como um ponto relevante e imutável, algo próprio da natureza humana e comum a todos.

A busca de respostas fora desse eixo mercado/mercadoria implica assumir um caminho tortuoso e complicado, sendo mais confortável, portanto, optar pela passividade, internalizar o discurso de que as coisas são como são, relegando ao esquecimento as contradições que, invariavelmente, emergem.

Neste sentido, afirma Lessa (2005, p. 71):

E este "domesticar" das contradições apenas é possível pela reprodução de uma concepção de mundo tão frouxa, tão pouco articulada, tão pobre, que torne aproblemáticas as contradições entre os conceitos e os valores que adotamos. Uma concepção de mundo irracional o suficiente para que as absurdas contradições entre nossas idéias e valores não causem maiores perturbações, nem intelectuais nem afetivas. 
Esse percurso cômodo traduz-se em superficialidade teórica, de modo que a curiosidade, outrora tão associada à natureza humana, vai se tornando, cada vez mais, rara e, até mesmo, indesejada, pois o prazer pelo saber cede espaço aos consolos trazidos pela aquisição de mercadorias.

Afinal, se mercado é sinônimo de progresso, não importa o rumo que as coisas tomem, porque estaremos nas melhores mãos. Em sendo assim, porque não aceitar que nossas próprias relações sociais também se pautem nas relações que temos com as mercadorias?

Nossa atual forma de conceber o mundo e nossa exacerbada ocupação com o imediato nos permite esquecer, por exemplo, que:

[...] o passado consubstancia as determinações causais que explicam por que somos o que somos e não somos diferentes; o futuro é um elemento importante a determinar a qualidade de nossas reações ao que somos, pois, em parte, nossas reações ao presente são determinadas pelo que almejamos vir a ser. (LESSA, 2005, p. 71-72)

Estabelecidos esses marcos iniciais, resta esclarecer que o objeto do presente estudo é discutir o mundo do trabalho contemporâneo, sem descuidar dos caminhos que nos conduziram até aqui. Obviamente, trata-se de um esforço impossível de se realizar em poucas páginas. Contudo, espera-se que, suscitar o tema e estabelecer alguns pontos centrais, seja relevante para futuros aprofundamentos.

\section{Como esclarece Lessa (2005, p. 75)}

O trabalho, para ficarmos com nosso objeto, apenas pode ser a "categoria eterna do mundo dos homens porque assume, a cada instante da história, configurações distintas que são irrepetíveis (portanto, únicas), pois portadoras de todo o desenvolvimento passado.

Por assim ser, busca-se, neste estudo, focar em, apenas, uma pequena parte dessas questões já suscitadas. O mundo que envolve o estudo do trabalho é nebuloso e demasiadamente complexo. Pretende-se esboçar respostas a perguntas como: o trabalho sempre foi da forma como o conhecemos hoje? O trabalho existe para além do mercado? Como ficará o trabalho sem empregos?

A fim de alcançar esse desiderato, buscaremos demonstrar, em um primeiro momento, as transformações do mundo do trabalho, desde a fase pré-capitalista, até o mundo contemporâneo, marcado pela globalização econômica e pela financeirização da riqueza. 
Enfrentar-se-ão alguns aspectos da chamada "crise" do emprego no mundo contemporâneo, decorrente dessas transformações, com a perda de hegemonia do trabalho face à sua frequente subdivisão e desqualificação.

Por fim, discutir-se-ão possíveis caminhos, com destaque ao terceiro setor e à necessidade de cooperação e de reencontro do trabalho com a comunidade, desatrelando-se o valor humano das ideias de produtividade e de consumo, voltadas, unicamente, ao mercado.

\section{O TRABALHO NO MUNDO PRÉ-CAPITALISTA}

Neste resgate histórico modesto, o primeiro ponto a ser considerado é que o trabalho, nos moldes similares aos que conhecemos hoje, é uma invenção moderna, que foi universalizada com o industrialismo.

Na verdade, durante boa parte da história da humanidade, o trabalho sequer era visto como uma fator de integração social. Ao contrário. O trabalho voltado para a subsistência era um forte elemento desagregador pois estava vinculado à necessidade, sobretudo na Antiguidade.

Isso é revelado pelo pensamento de Aristóteles (apud Arendt, 2014, p. 14) para quem existiam três modos de vida que podiam ser, livremente, escolhidos pelos homens, sendo que nenhum deles incluía qualquer atividade dedicada à preservação da vida. Poder-seia, assim, optar por um modo de vida ligado ao deleite dos prazeres, um outro, ligado à vida dedicada a pólis e, um terceiro, que constituía a vida do filósofo.

A necessidade era típica do reino natural, do déspota, incompatível com qualquer noção de liberdade que apenas era possível para além das amarras do corpo, ultrapassando-se uma esfera de produção material.

Não é que não se desenvolvesse o trabalho ou que não existisse economia, mas era restrita à atividade familiar, portanto, à privada. O sujeito apenas era livre e igual na polis, espaço público.

A esfera privada, aquela da família, confundia-se, pois, com a esfera da necessidade econômica e do trabalho, ao passo que a esfera pública, política, aquela da liberdade, excluía rigorosamente as atividades necessárias ou úteis da esfera dos "assuntos humanos". (GORZ, 2003, p. 23) 
Os cidadãos pertenciam às duas esferas. Cabia-lhes, através do uso da violência unicamente justificável no domínio do lar - contra mulheres e escravos, passar o menor tempo possível na esfera privada, o suficinete para por termo às suas necessidades, a fim de poder gozar a liberdade e a igualdade da esfera pública, exercer a ação e o discurso, nas praças da pólis (GORZ, 2003; ARENDT, 2014).

Como destaca Arendt (2014, p. 29):

Ser político, viver em uma pólis, significava que tudo era decidido mediante palavras e persuasão, e não força e violência. Para os gregos, forçar pessoas mediante a violência, ordenar ao invés de persuadir, eram modos pré- políticos de lidar com as pessoas, típicos da vida fora da pólis, característicos do lar e da vida em família, em que o chefe da casa imperava com poderes incontestes e despóticos.

Portanto, vida privada significava, para os antigos, estar privado de alguma coisa, sobretudo, da possibilidade de alcançar as capacidades humanas tidas como mais elevadas. Ainda, estar na esfera privada ou viver unicamente nela deixava de ser inteiramente considerado como humano (ARENDT, 2014).

Séculos mais tarde, com a queda do Império Romano e a ascensão da Igreja Católica, já na Idade Média, essa separação entre as esferas da vida ainda persistia, obviamente, bastante distinta, mas com semelhanças com o cenário anterior. Opunham-se, às trevas do dia a dia, as maravilhas do que é divino e, conforme o feudalismo fora se afirmando, com o império do senhor feudal sobre a vida das famílias, do secular sobre o religioso, o espaço privado passou a prevalecer sobre um espaço público, praticamente, inexistente.

Embora só com alguma dificuldade seja possível equacionar o público com o religioso, realmente o domínio secular, sob o feudalismo, era inteiramente aquilo que o domínio privado havia sido na Antiguidade. Sua marca distintiva era a absorção de todas as atividades na esfera do lar - onde tinha significação apenas privada - e, consequentemente, a própria ausência de um domínio público. (ARENDT, 2014, p. 41)

Em tal contexto, todas as atividades desempenhadas pelo homem, inclusive, nas organizações profissionais tipicamente medievais, como as guildas, bem como todas as suas relações foram transferidas para o domínio privado. O próprio conceito de bem comum, nesse período, dizia respeito ao ambiente privado e à confluência de interesses, tanto materiais, quanto espirituais, que deveriam ser buscados e preservados (ARENDT, 2014, p. 42).

Até então sequer se poderia falar em sociedade. Arendt (2014, p. 46) situa o surgimento da sociedade quando da ascensão dessa esfera privada, em outros termos, quando 
a rotina, os problemas e a estrutura organizacional do lar extrapolaram esse limite restrito e ganharam o espaço público. Nesse momento, os espaços público e privado tornaram-se quase irreconhecíveis.

O espaço privado ganhou outro sentido, não era mais um campo de privações, nem de violência, e sim, um espaço privilegiado para o exercício da intimidade. Deixou de ser contraposoa à esfera política para ser confrontado com um campo muito mais apropriado, o da esfera social (ARENDT, 2014, p. 47).

Uma das características mais marcantes da sociedade, descrita por Arendt (2014, p. 55), é sua tendência por se expandir e para englobar, tanto os domínios políticos e privados mais antigos, como a própria intimidade. Nota-se, por exemplo, que ela impõe exigências niveladoras, atribui e espera que cada um desempenhe um papel específico, baseado em regras e em força. A própria economia, por exemplo, em sua acepção mais moderna, atende a essa finalidade, tornando-se ciência apenas quando o homem passou a atentar a determinados padrões, definidos no seio social.

A noção de trabalho, nessa virada de pensamento, também sofreu profundos e definitivos impactos:

A indicação talvez mais clara de que a sociedade constitui a organização pública do processo vital encontra-se no fato de que, em um tempo relativamente curto, o novo domínio social transformou todas as comunidades modernas em sociedades de trabalhadores e empregados (...). A sociedade é forma na qual o fato da dependência mútua em prol da vida, e de nada mais, adquire importância pública, e na qual se permite que as atividades relacionadas com a mera sobrevivência apareçam em público. (ARENDT, 2014, p. 56)

Essa libertação do trabalho, por assim dizer, permitiu o "artificial crescimento do natural", ou seja, trouxe à tona a preocupação de expandir, de forma constante e acelerada, a produtividade do trabalho, mesmo antes da Revolução Industrial. Nesse contexto, a organização da atividade do trabalho, mais conhecida como divisão do trabalho, representa um marco fundamental no modo como entendemos o trabalho nos dias atuais (ARENDT, 2014, p. 57).

Segundo Arendt (2014, p. 58-60), em nenhuma esfera da vida o homem atingiu tamanho nível de excelência quanto na do desenvolvimento da atividade do trabalho. O termo trabalho, que, historicamente, sempre possuíra uma conotação negativa, tornou-se o campo para o desenvolvimento da excelência. Assim, o trabalho migrou, definitivamente, para o espaço 
público já que nem “[...] a educação, nem a engenhosidade, nem o talento podem substituir os elementos constitutivos do domínio público, que fazem dele o local adequado para a excelência humana".

Contudo, até o século XVIII, ainda que se considerem as transformações na concepção do termo trabalho, ele restringia-se aos servos e aos trabalhadores de jornada, responsáveis pela produção dos bens de consumo e serviços necessários à sobrevivência. De outro lado, por exemplo, os artesãos, responsáveis pela produção de bens duráveis, não trabalhavam, e sim elaboravam obras e lançavam mão do trabalho dos servos nas etapas de produção consideradas mais penosas, pelo que percebiam um salário (GORZ, 2003).

Faltava, até esse momento, uma característica essencial ao trabalho como o conhecemos hoje, ausente na fase em que o capitalismo inicia sua fase mercantil e, até mesmo, no período inicial do capitalismo industrial: a racionalidade econômica.

A tecelagem, uma das atividades humanas mais tradicionais, realizada em ambiente doméstico, por exemplo, em meados do século XIX, era muito mais do que um modo de subsistência: era um modo de vida, pautado em tradições e fortemente considerado até mesmo pelos capitalistas. (GORZ, 2003)

Segundo Gorz (2003, p. 24):

Parte interessada em um sistema de vida que concilia os interesses de um e de outros, os comerciantes sequer imaginavam poder racionalizar o trabalho dos tecelões em domicílio, introduzir entre ele a concorrência, buscar racional e sistematicamente maiores lucros.

Enquanto a racionalidade econômica não se impôs, por força da tradição e de outros tipos de racionalidade e interesses que serviam de limite ao econômico, o capitalismo industrial não pôde se desenvolver. Conforme Gorz (2003, p. 27):

É o que dizem, aliás, Marx e Engels no Manifesto Comunista, embora de outra perspectiva: a burguesia, afirmam, rasgou enfim o véu que até então mascarara a verdade das relações sociais: "Todos os elos, complexos e variados, que uniam o homem feudal a seus superiores, ela rompeu sem piedade; não deixou outro laço entre o homem e seu próximo além do frio interesse... No lugar da exploração dissimulada das ilusões religiosas e políticas, ela introduziu uma exploração aberta, desavergonhada, direta, árida...". Ela "rasgou o véu dos sentimentos e das emoções próprias às relações familiares e reduziu-os a simples relações monetárias... Foi ela quem, primeiro, mostrou de que é capaz a ação humana..." "No espaço que mal cobre um século de dominação, a burguesia criou forças produtivas mais numerosas e mais colossais do que foram capazes todas as gerações antes dela". 
Portanto, em linhas gerais, essas são as bases da transformação, não de um conceito de trabalho em si, que é mais recente, mas, fundamentalmente, do modo de compreender o trabalho que permite, inclusive, poder pensar no trabalho como o conhecemos hoje, inserido em um contexto capitalista, em que ele deixou de ser algo negativo, ligado à sobrevivência e à necessidade, para ser um terreno apropriado para o desenvolvimento da excelência, ocupado em expandir cada vez mais o natural, ao mesmo tempo que fomentava contradições, vez que era pautado por uma racionalidade econômica que desconsiderava limites e ideologias.

\section{O CAPITALISMO E AS TRANSFORMAÇÕES DO TRABALHO}

Buscou-se, até aqui, traçar um esboço das transformações enfrentadas pelo trabalho até o momento em que surgiu uma racionalidade econômica, transformando e dissolvendo, profundamente, a estrutura social que havia até então. A partir dele, podemos começar a vislumbrar o trabalho em sua acepção moderna.

O trabalho, nos termos que conhecemos hoje, é realizado na esfera pública, ele é solicitado, considerado útil e, fundamentalmente, remunerado. Este trabalho é gerador e razão da nossa existência, confere-nos uma identidade social que nos permite ter direitos e deveres compartilhados socialmente. Segundo Gorz (2003) esse trabalho socialmente remunerado é o fator preponderante da socialização.

Como mencionado, esse desenho começou a ser traçado a partir do capitalismo manufatureiro do século XVIII e se intensificou com o advento do capitalismo industrial.

O marco central nesse processo, como afirmado, foi a ascensão e a consolidação de uma racionalidade econômica peculiar ao capitalismo. Trata-se, nos termos propostos por Gorz (2003, p. 28), de um “reducionismo unidimensional”, à medida em que sufoca qualquer valor e finalidade considerada irracional, na visão econômica.

Assim, modelos tradicionais, que, anteriormente, eram considerados como pontos de partida para os avanços e as transformações dos modos de produção, são dissolvidos. Tal racionalidade não fica restrita ao meio econômico de trocas de bens e serviços, ela se espalha por todas as diferentes relações sociais. O que passa a reger a sociedade são as relações 
monetárias (entre indivíduos), de força (entre as classes) e instrumental (diante das relações entre homem e natureza) (GORZ, 2003, p. 28).

Foi nesse contexto que surgiu a classe proletária, composta por aqueles que só tinham prole, desprovidos de propriedade e vistas como, pouco mais, do que uma força de trabalho disponível para ser trocada. Afirmaram-se as forças produtivas em detrimento de uma organização do trabalho pelos próprios trabalhadores, que tiveram sua condição humana cada vez mais reduzida.

Assim, o trabalho, com seu potencial de libertação das amarras antigas, foi transformado, pelo capitalismo, contraditoriamente, novamente, em algo servil e destituído de um conteúdo humano.

É essa contradição que se transforma no sentido e no motor da História: graças à racionalização capitalista, o trabalho deixa de ser atividade privada submetida às necessidades naturais; mas, no momento mesmo em que é despojado de seu caráter limitado e servil para tornar-se poiêsis, afirmação da potência universal, ele também desumaniza aqueles que o realizam. (GORZ, 2003, p. 28)

Uma preocupação que se afirmou nesse período foi o custo do trabalho. De acordo com essa nova racionalidade econômica, era imperioso saber, exatamente, quanto custava a mão de obra, bem como torná-la previsível, ou seja, calcular quanto cada trabalhador pode render, independentemente de qualquer consideração ou motivação individual, medidas que passaram a ser necessárias para que os investimentos capitalistas não fossem desperdiçados. (GORZ, 2003, p. 29)

Nota-se que, a partir de então, o trabalhador passou a a ser visto como uma engrenagem intercambiável da grande máquina capitalista, substituível por qualquer outra, a qualquer tempo. O próprio trabalho ganhou traços de uma máquina, exigindo-se ritmo e cadência, antes, inexistentes pois, como esclarece Gorz (2003, p. 29), “(...) para os operários dos fins do século XVIII, o 'trabalho' era uma atividade intuitiva, integrada a um ritmo de vida ancestral", não havendo aquele tempo um preocupação em se trabalhar mais para ganhar mais.

A falta de preocupação do operário em trabalhar mais para ganhar mais ou, em outros termos, em entregar-se a intermináveis jornadas de trabalho diárias, foi uma das barreiras que forçaram muitos dos primeiros industriais a fecharem as portas. A persistência de um 
ritmo de trabalho antigo foi, deliberadamente, confundida pela burguesia como demonstrações de preguiça e indolência (GORZ, 2003).

Duas consequências, ao menos, podem ser observadas. A primeira é que, o pagamento de salário em função da produção, tornou-se impraticável, de sorte que os capitalistas reduziram, mais e mais, os salários a fim de que os operários dedicassem a maior parte possível de tempo à fábrica. A segunda, foi o recrutamento, pelas indústrias, de crianças como mão de obra (GORZ, 2003).

Percebe-se que as transformações impostas pela racionalidade econômica foram decisivas e consistiram em

[...] uma revolução, uma subversão do modo de vida, dos valores, das relações sociais e das relações com a natureza, uma invenção, no sentido pleno de termo, de algo que jamais existira antes. A atividade produtiva desfazia-se de seu sentido original, de suas motivações e de seu objeto para tornar-se simples meio de ganhar um salário. Deixava de fazer parte da vida para tornarse o meio de "ganhar a vida". O tempo do trabalho e o tempo de viver foram desconectados um do outro; o trabalho, suas ferramentas, seus produtos, adquiriram uma realidade separada do trabalhador e diziam agora respeito a decisões estranhas a ele. A satisfação em "fazer uma obra" comum e o prazer de "fazer" foram suprimidos em nome das satisfações que só o dinheiro pode comprar. (GORZ, 2003, p. 30)

A difusão da racionalidade econômica foi, assim, uma condição fundamental e necessária para que a empresa capitalista pudesse prosperar. A previsibilidade e o cálculo não ficaram mais restritos a atividade em si, pois quanto maior era o investimento, maior a necessidade de controle, tanto nas esferas jurídicas e políticas, quanto nas administrativas e culturais. Nada podia escapar; até a própria vida dos indivíduos deveria ser conduzida de forma racional e calculável.

Daí decorre outra consequência importante para o mundo do trabalho: quanto mais as esferas da atividade foram se racionalizando e se diferenciando, maior foi a complexidade que acabaram por atingir, tornando-se autônomas. Essa complexidade traduz-se em uma gama de subdivisões, competências e tarefas, enfim, funções cada vez mais especializadas. Como esclarece Gorz (2003, p. 39):

À medida que se torna mais complexa, a organização das funções especializadas, em vista da tarefa que ultrapassa e unifica de fora seus agentes, responde cada vez menos às motivações que têm esses últimos para se conduzirem de maneira racional com relação à tarefa prevista. Para que cooperem a sua realização, não se pode apostar em suas disposições, capacidades e boa vontade pessoais. Sua fiabilidade só será assegurada pela codificação e pela regulamentação formais de suas condutas, de suas tarefas e suas relações. 
A burocratização e a diferenciação crescentes, tanto no que diz respetio ao aparato administrativo, quanto ao econômico, fizeram com que o sujeito se tornasse, apenas, uma engrenagem de uma grande máquina, na qual ele era dispensável.

Uma consequência, apontada por Gorz (2003, p. 40), da esfera da heteronomia é que, o volume das especialidades, bem como o aparato e o tamanho das empresas, muitas vezes dispersas pelo mundo, produzindo peças para um único produto, retirou, sobremaneira, a possibilidade de as pessoas se autogerirem, o que representou uma completa inversão com relação ao que ocorria nas comunidades de trabalho.

No modelo taylorista de organização científica do trabalho, por exemplo, a cooperação autorregulada não foi completamente eliminada, ocorrendo, minimamente, na distribuição e na organização do trabalho em pequenos grupos; contudo, representava “(...) apenas um elemento subordinado à integração funcional dos indivíduos e dos grupos como engrenagens de uma maquinaria que os ultrapassa e domina." (GORZ, 2003, p. 40).

Portanto, a integração entre os trabalhadores já não mais podia ocorrer de modo social. Dava-se de forma funcional, tamanho era o elo de subdivisões e de especializações do trabalho, de modo que os trabalhadores se tornaram incapazes de firmar, como outrora, elos de cooperação. A funcionalização não apenas se instalou como se perpetuou, como elemento necessário a garantir a previsibilidade e a calculabilidade da força de trabalho (GORZ, 2003).

Ora, como a integração funcional não era viabilizada por um apelo à cooperação ou a um dever profissional, necessitava de instrumentos que permitissem a submissão do trabalhador à sua lógica.

O primeiro passo nessa direção foi o uso da coerção física e psicológica. E o Estado foi essencial nesse contexto, promulgando leis rigorosas de controle daqueles que não trabalhavam, os quais eram considerados "vagabundos" e "malandros".

Além disso, o próprio welfare state, por força do capital, foi transmutado - no Reino Unido, por exemplo - em workfare, através de uma legitimação ou um reforço estatal da tese de que a cidadania se conquista, única e exclusivamente, através do trabalho, que é, portanto, uma “obrigação de cidadania”, um “dever cívico” (WACQUANT, 2011, pp. 51-52).

No plano do discurso, os Estados comportavam-se como se desconhecessem as mazelas sociais e econômicas, exaltando a responsabilidade individual. Aqueles pobres incapazes de trabalhar seriam incompetentes socialmente e, no plano moral, demonstravam 
imperícia. A solução seria, então, um Estado forte, capaz de impor a disciplina do trabalho (WACQUANT, 2011).

Em tal contexto aflora também o discurso de uma "sociedade meritocrática" alcançada, segundo Wacquant (2011, p. 55), pela:

[...] supressão da divisão em classes sociais, vantajosamente substituída pela oposição técnica e moral entre os "competentes" e "incompetentes", os "responsáveis" e os "irresponsáveis", as desigualdades sociais sendo apenas um reflexo dessas diferenças de "personalidade".

Portanto, o pobre era pobre por sua própria culpa; o seu comportamento é que era problemático, o que impunha a supervisão, acorreção e a imposição do trabalho como requisito essencial, até mesmo, para a obtenção de subsídios junto ao Estado.

Além da coerção, outros instrumentos que motivavam a trabalhar, consoante Gorz (2003, p. 43), eram os chamados instrumentos reguladores, subdivididos em dois tipos: os reguladores incitativos (dinheiro, segurança, poder e prestígio relacionados à alguma função) e os reguladores prescritivos (responsáveis por constranger o indivíduo, por imporem uma conduta considerada funcional).

Assim, o primeiro passo na imposição do trabalho funcionalizado era a coerção, minorada quando era possível controlar o trabalhador por outros meios:

Só pode afrouxar a coerção quando puder motivar os trabalhadores, através de "reguladores incitativos", a prestarem-se de bom grado a um trabalho cuja natureza, ritmo e duração são programados de antemão pela organização da fábrica ou do escritório, um trabalho que é impossível gostar. (GORZ, 2003, p. 51)

O mais importante, nesse contexto, é que a heterorregulação acabava por impactar a sociedade, promovendo uma cisão interna cada vez mais profunda:

De um lado, a massa da população, que fornece um trabalho cada vez mais especializado e predeterminado, é motivada por fins incitativos sem coerência alguma com a finalidade das organizações nas quais é funcionalmente integrada. De outro, uma pequena elite de organizadores tenta assegurar a coordenação, as condições de funcionamento e a regulação das organizações em seu conjunto, determina as finalidades e a estrutura (o organograma) das administrações correspondentes e define os mecanismos reguladores, incitativos e prescritivos mais funcionais. Existe, portanto, uma cisão entre a sociedade cada vez mais manipulada, cada vez mais funcionalizada, e a administração pública e privada cada vez mais invasiva; existe um divórcio entre a esfera civil, autorregulada, cada vez mais reduzida, e um Estado dotado de poderes de heterorregulação cada vez mais extensos que exige o funcionamento das máquinas administrativas e dos serviços públicos referentes ao próprio Estado. (GORZ, 2003, p. 43) 
Há, neste paradoxo de racionalidades conflitantes, segundo Gorz (2003), um gérmen para o esfacelamento da própria sociedade e da vida dos indivíduos, à medida em que, tanto a vida profissional, quanto a pessoal, eram dominadas por valores irracionais. Nesse sentido, afloraram as competitividade, a necessidade de ser bem-sucedido e a alienação em relação aos superiores, dentre outros aspectos. Como recompensa, os salários e o êxito permitiam, na vida privada, o conforto e a segurança do lar, pouco importando, na maioira das vezes, o percurso para se chegar a eles.

Defrontamo-nos, então, com outra importante questão. Superada a necessidade de impor uma racionalidade econômica ao trabalho, ou seja, a de fazer com que se trabalhe, não importando o quanto, nem como, nem quais as consequências do trabalho, desde que o pagamento aconteça no final do mês, surgiu outra: como o trabalhador gastará esse dinheiro? O indivíduo passou, de operário e produtor, a um trabalhador e consumidor, que deve ser ensinado a consumir, da mesma forma que foi ensinado a trabalhar.

O termo consumo, como o entendemos hoje, também foi forjado na modernidade. Até pouco mais de um século atrás não havia nele qualquer conotação positiva. Significava, basicamente, destruição e exaurimento, termos fincados, fortemente, no terreno da violência. Tratava-se de um vício que, posteriormente, foi elevado a uma espécie de virtude (RIFKIN, 2004).

Como aludido anteriormente, durante a maior parte da história da humanidade as pessoas preocupavam-se, basicamente, com o necessário à sua sobrevivência. $\mathrm{O}$ trabalho empregado visava a garantir esse básico; o tempo excedente era destinado ao lazer, o que foi, radicalmente, alterado pela racionalidade econômica que precisava de trabalho constante, como meio de garantir o sucesso do empreendedor capitalista.

Assim, se era necessária uma força de trabalho constante, também era imperiosa a necessidade de consumidores, constantemente ávidos por novos produtos. E, mais uma vez, assim como com o trabalho, a coerção, calcada em um discurso empresarial da diferenciação de classes e nas vantagens da modernidade, disfarçada, portanto, também foi essencial para instalar um novo padrão de consumo. Nesse sentido, Rifkin (2004, p. 20) esclarece que:

Os anunciantes passaram a desviar rapidamente seus apelos de venda dos argumentos utilitários e informações descritivas do produto para apelos emocionais por status e diferenciação social. O homem e a mulher comuns eram estimulados a seguir o exemplo dos ricos, a adotar a aparência de riqueza e prosperidade até então restrita à aristocracia empresarial e à elite social. 
Rapidamente, sobretudo nos tempos de crise do consumo, o próprio Estado redirecionou seus esforços para o estímulo ao consumo, como forma de resposta às dificuldades enfrentadas. Nesse cenário, a ideia de crédito ao trabalhador-consumidor mostrou ser o caminho mais viável para instalar, definitivamente, uma ideologia do consumo (RIFKIN, 2004).

Buscou-se, até aqui, demonstrar como a ideia do trabalho foi sendo forjada ao longo da história. Obviamente o estudo não tem por objetivo esgotar o assunto, já que inúmeros outros desdobramentos podem ser estabelecidos na análise até aqui empregada. Pretendeu-se, tão somente, demonstrar como o trabalho assume um papel central na vida dos indivíduos e como a racionalidade econômica, drasticamente, transformou a vida de todos nós, que deixamos de nos preocupar com a cooperação social e a produção para a subsistência, para nos tornarmos consumidores dependentes, quase que exclusivamente, do mercado.

Ocorre que esse modelo já dá sinais de saturação diante da globalização já que o elemento central - o emprego - é posto em xeque, quer pelos avanços tecnológicos, quer pelas práticas empresariais pautadas nessa nova lógica, dentre outros fatores.

\section{A CRISE DO EMPREGO NO MUNDO CONTEMPORÂNEO GLOBALIZADO}

A história das civilizações, sobretudo das modernas, como referido no tópico anterior, está intimamente ligada à categoria trabalho. Contudo, pela primeira vez, o trabalho humano está sendo eliminado de forma sistemática, em todo o mundo, das linhas de produção, de escritórios, dos bancos e do campo, dentre outors setores.

Em seu lugar, são colocadas máquinas e equipamentos que vêm permitindo, em escala crescente, uma revolução produtiva. Mesmo os novos empregos que são criados nesse cenário perderam muito do valor e do prestígio de que antes desfrutavam. Agora, encontramse, sobremaneira, trabalhos precários e baixos salários.

Não se trata de uma posição ou de um questionamento isolado. Silva (2008) levanta algumas questões centrais, como: existe uma crise do trabalho? Qual o papel que o trabalho ocupa, atualmente, na vida das pessoas? O ambiente de trabalho ainda é um espaço favorável para a inclusão social? 
A resposta para a primeira pergunta é positiva. $\mathrm{O}$ incremento do debate sobre o trabalho se dá em um momento de declínio do papel que o trabalho ocupa na vida das pessoas, podendo-se falar, conforme Silva (2008), em uma crise na sociedade do trabalho, modelo fortemente fincado na história das sociedades ocidentais desenvolvidas e composta por quatro pilares básicos: empresa industrial capitalista, o trabalhador assalariado, o mercado de trabalho e a ética do trabalho.

A empresa industrial capitalista - que retira o trabalhador da unidade familiar, levando o trabalho para a esfera pública e que pauta suas atividades em uma racionalidade econômica -, constituiu-se como o grande paradigma após a Revolução Industrial, expandindo sua racionalidade para as diversas relações estabelecidas em sociedade.

Silva (2008) aponta algumas razões que podem explicar porque o trabalho, em sua acepção moderna, vem perdendo sua hegemonia: (i) nota-se uma crescente subdivisão e desqualificação do trabalho, que, em muitos casos, elimina a capacidade de gerar satisfação nas pessoas; (ii) a diminuição massiva dos postos de trabalho faz com que muitos nem consigam ingressar no mercado de trabalho; e (iii) o desemprego e o maior tempo livre fazem com que o trabalho represente, apenas, uma parcela do tempo de convívio social das pessoas.

Além disso, nota-se o incremento da exclusão social daqueles menos aptos a concorrer nesse novo cenário, agravada pela globalização e pela imposição de uma grande flexibilidade, tanto para os trabalhadores, quanto para as empresas. Esse cenário impacta a ética do trabalho, pois há aumento do tempo livre e, simultaneamente, aumento do desemprego prolongado.

Resta claro, portanto, que há, sim, uma crise do trabalho modernamente forjado e que a categoria trabalho, em si, perdeu a capacidade de, sozinha, dar conta da realidade e dos interesses sociais.

Trata-se de um problema enfrentado, tanto pelos países considerados desenvolvidos, quanto pelos em desenvolvimento. Estes últimos sofrem, especialmente, com a criação de fábricas de ponta em todo o mundo, que dispensam os trabalhadores e os substituem por maquinários, muito mais produtivos, eficientes e baratos.

De outro lado, a substituição por máquinas não ocorre mais, exclusivamente, naqueles postos de trabalho menos qualificados; as novas tecnologias prometem - e já o fazem 
- avançar sobre aquele trabalho mais intelectualizado que sempre foi privilegiado. Contudo, a situação é particularmente mais grave para o primeiro grupo já que, segundo Rifkin (2004) uma parcela significativa da força produtiva, na ordem de $75 \%$, desempenha atividades consideradas repetitivas e facilmente substituíveis por máquinas.

Os trabalhadores ainda sofrem com um problema que lhes diz, ainda menos, respeito: o dilema entre concorrência global e encargos trabalhistas. Neste confronto, prevalece o comportamento das empresas de investir em custos de capital, ao invés de contratar novos trabalhadores; em outros termos, nesse novo contexto empresarial, as máquinas são, cada vez mais importantes, que as pessoas. E com a adequação das empresas à alta tecnologia, esse fenômeno se torna sem precedentes já que, pensar, não é mais exclusividade humana.

Como aduz Rifkin (2004, p. 11):

A introdução de tecnologias mais sofisticadas associadas a ganhos de produtividades significa que a economia global pode produzir um número cada vez maior de bens e serviços empregando uma porcentagem cada vez menor da força de trabalho disponível.

No passado, a característica central diante das inovações tecnológicas é que a mãode-obra desempregada por esse motivo era absorvida por um novo setor, que surgia para absorver a força de trabalho excedente. Atualmente, isso não ocorre: os setores vêm, gradualmente, sucumbindo, sem que se consiga oferecer alternativas. No horizonte próximo, como aponta Rifkin (2004), percebe-se o incremento do setor do conhecimento, incapaz, pela sua própria natureza, de suprir a escassez de emprego.

Pensando nesse setor do conhecimento, os EUA, durante o governo de Clinton (1993-2001), estruturou uma política pública destinada ao retreinamento dos desempregados, visando torná-los aptos a concorrer nesse novo mundo, contudo, o projeto teve êxito inexpressivo, já que:

É ingenuidade acreditar que grandes números de trabalhadores sem qualificação e semiqualificados, trabalhadores administrativos e operários possam ser treinados para tornarem-se físicos, cientistas de computação, técnicos de alto nível, biólogos moleculares, consultores empresariais, advogados, auditores etc. (RIFKIN, 2004, p. 37)

Na verdade, existem "abismos" educacionais, intransponíveis por programas de retreinamento. E, ainda que isso fosse possível, o setor de conhecimento não conseguiria abrigar todos os desempregados. 
Rifkin (2004, p. 61) trata a ascensão da sociedade da informação e de um mundo sem trabalhadores, após a Segunda Guerra mundial, como uma Terceira Revolução Industrial. O que a faz ser diferente das demais é que esta alcança e é capaz de substituir a mente humana, pois "os computadores estão assumindo tarefas cada vez mais complexas e, no processo, mudando fundamentalmente nossos conceitos de individualidade e sociedade".

Neste processo de substituição do homem pela máquina, Rifkin (2004) considera que o exemplo mais trágico e, também, o pano de fundo para se compreender o problema foi o que aconteceu com a maior parte da população negra dos Estados Unidos, que acabou sendo substituída pelas máquinas e, posteriormente, jogada nos guetos, marginalizada como uma subclasse dependente de programas sociais.

Os negros foram, duplamente, substituídos pelas máquinas, pois, ao viverem em situação precária como meeiros - analogamente à escravidão - nos campos de algodão do Sul, foram substituídos, na década de 1940, pelas colheitadeiras que, sozinhas, realizavam o trabalho de 50 pessoas. Como não eram proprietários da terra, acabaram expulsos, desempregados e despossuídos migrando, massivamente, para as grandes cidades em busca de emprego na indústria que, também, enfrentava um processo de automação. Rifkin (2004, p.

75) exemplificava esse fato com a informação de que, em 1960, “apenas 67 negros estavam entre os mais de 11 mil operários qualificados na folha de pagamento" da General Motors.

O fato é que:

Com a introdução das máquinas automatizadas, foi possível substituir, a um custo menor e por formas inanimadas, milhões de afro-americanos que, durante muito tempo, permaneceram na base da pirâmide econômica, primeiro como escravos nas lavouras, depois como meeiros e, finalmente, como operários não qualificados nas fábricas e forjarias do norte. (RIFKIN, 2004, p. 79)

Segundo Rikin (2004), com a automação, pela primeira vez, na história, os negros foram desnecessários e, lamentavelmente, descartados:

Derrotados e esquecidos, milhares de americanos negros urbanos extravasavam sua frustração e raiva tomando as ruas dos guetos urbanos em todo o país. (...) Após os tumultos de Watts, um dos habitantes locais fez uma advertência lacônica que exprimia a ira há tanto tempo reprimida e que havia desencadeado o tumulto. "Os brancos", declarou, "pensam que podem simplesmente encurralar as pessoas em uma área como Watts e depois esquecê-las. Não funcionou". (RIFKIN, 2004, p. 79) 
Tais fenômenos históricos irradiam seus efeitos até os dias de hoje. Milhares de negros norteamericanos permanecem como subclasse, à margem da economia global da alta tecnologia.

O avanço das máquinas não foi, contudo, o único fator a determinar a crise de empregos. Durante muito tempo, cerca de 40 anos, as empresas americanas conviviam com um aparente paradoxo de produtividade. Foram realizados inúmeros investimentos em tecnologia da informação, mas os ganhos em produtividade ficaram aquém do esperado. $\mathrm{O}$ motivo não foi óbvio, no início, mas dizia respeito menos à tecnologia, do que à estrutura organizacional das empresas. Voltou-se, então, para a busca de reduzir o tamanho das empresas e reorganizá-las para um novo cenário:

Corporações e empresas americanas em todo o mundo foram estruturadas há um século para produzir e distribuir bens e serviços em uma era de transporte ferroviário e de comunicação telefônica e postal. Seu aparato organizacional mostrou-se totalmente inadequado para lidar com a velocidade, agilidade e habilidade de coleta de informação da era da tecnologia do computador. (RIFKIN, 2004, p. 92)

Foi no Japão do Pós-Segunda Guerra, em suas fábricas de automóveis, sobretudo a Toyota, que surgiu um novo modelo de fabricação que, por ser tão diferente daquele praticado nos EUA, acabou por ser chamado de produção pós-fordismo ou toyotista, que se caracterizava por uma produção enxuta que combinava novas técnicas gerenciais com maquinários cada vez mais modernos, produzindo-se mais com menos recursos e menos pessoas.

Contudo, no Japão, o tratamento conferido aos empregados era diferente, pois não eram considerados meros fatores de produção; cada um representava parte importante no processo da empresa e as estruturas hierárquicas foram trocadas por equipes cooperativas, com uma maior em gerar mais igualdade e menos atritos hierárquicos.

A disseminação desse novo modelo para as demais atividades e setores da economia, em diversos países, é conhecida, genericamente, como reengenharia. A revisão dos processos empresarias, somada à tecnologia de informação, vêm acabando com milhões de postos de emprego, atingindo, tanto os trabalhadores menos qualificados, quanto os gerentes médios, em estruturas organizacionais cada vez mais enxutas, com fluxo direto de informações e rápida comunicação.

Como pontua Rifkin (2004, p. 106): 
O processo de reengenharia está apenas começando e o desemprego já está aumentando; o poder aquisitivo dos consumidores está caindo e as economias domésticas cambaleando em consequência do impacto do achatamento das gigantes burocracias corporativas. Todos esses problemas devem se agravar dramaticamente nos próximos anos, à medida que as empresas, enfrentando a crescente e acirrada concorrência global, usem tecnologias de informação e telecomunicações progressivamente mais sofisticadas para aumentar a produtividade e reduzir os requisitos da mãode-obra.

A pergunta que muitos trabalhadores fazem, de modo desesperado, é se, de fato, ainda podem vir a ocupar algum lugar nesse mundo que se desenha. Assim, resta-nos discutir caminhos para além do paradigma clássico do emprego, assunto que, ainda, é tratado como um tabu, quase intransponível, que poucos estão dispostos a superar.

\section{O VALOR HUMANO DO TRABALHO PARA ALÉM DO MERCADO}

Como mencionado, o objetivo do estudo não é discutir alternativas ao emprego, e sim buscar realizar uma recuperação histórica do trabalho. Contudo, estaria incompleto sem que ao menos se aventasse alguma solução, ou caminho alternativo a ser aprofundado.

O valor humano na modernidade, como se entreviu até aqui, fora atrelado a uma ideia de produtividade. Todavia, em tempos em que máquinas substituem, maciçamente, os homens, onde residirá, afinal, o valor humano? Essa pergunta não pode ser respondida, adequadamente, sem que se destaquem as relações entre mercado e governo.

Se trabalhadores têm diminuída sua importância, o mesmo vem ocorrendo com os governos. Segundo Rifkin (2004), as grandes empresas multinacionais vêm ocupando posições tradicionais do Estado e exercendo um controle sem paralelo sobre os recursos globais, a mão de obra e o mercado, ao ponto de concentrarem grande parte do poder político estatal.

O fato é que, não são mais os Estados que ditam o ritmo do desenvolvimento. Conforme Ianni (2014, p. 16), as empresas, as corporações e os conglomerados transnacionais moldam a globalização:

Desenham as mais diversas cartografias do mundo, planejadas segundo as suas próprias políticas de produção e comercialização, preservação e conquista de mercados, indução de decisões governamentais em âmbito nacional, regional e mundial. 
Tornamos mercados e governos como elementos centrais e nos esquecemos que sua existência, como os conhecemos, é notadamente moderna e remonta uma história muito recente de pouco mais de 100 anos. Antes disso o trabalho era, fundamentalmente, privado, desenvolvido em ambiente familiar, livre da racionalidade econômica e, assim, mais sensível a uma troca pautada em necessidades da comunidade. (RIFKIN, 2004; SILVA, 2008; GORZ, 2003)

Assim, o valor humano, nesta nova era, poderia ser buscado no passado, diante da diminuição de importância, tanto de governos, quanto de mercados, cabendo ao povo, conforme Rifkin (2004, p. 238), restabelecer "mais uma vez, comunidades viáveis para amortecer tanto as forças impessoais do mercado global como as autoridades governamentais, cada vez mais fracas e incompetentes". Em outros termos:

Os talentos e a energia dos empregados, bem como o dos desempregados aqueles com horas livres e aqueles com horas ociosas - poderiam ser eficazmente direcionados na reconstrução de milhares de comunidades locais e na criação de uma terceira força que floresça independentemente do mercado e do setor público. (RIFKIN, 2004, p. 239)

Esse caminho alternativo não é algo a ser inventado. Ele já existe, mas é eclipsado pela visão restrita dos setores como públicos e privados. Trata-se, por exemplo, do setor voluntário, no qual os padrões de referência do mercado dão espaço às relações comunitárias. O seu motor é o tempo dispensado em ajudar ao próximo, materializando-se em inúmero exemplos, que vão, desde a ajuda a idosos, até a construção de casas para os mais necessitados, fomentando uma real integração social e não funcional (RIFKIN, 2004).

Cabe referir que, o setor independente nos Estados Unidos, alcançou um espaço considerável, inclusive, não inferior àqueles dos Estado e dos mercados. Contudo, sua importância em estudos científicos é mitigada. Nas escolas americanas, a íntima relação entre o povo americano e o serviço voluntário é ignorada; no seu lugar, são difundidas ideias sobre o êxito do mercado e a importância do equilíbrio trazido pelo sistema representativo de governo. E, visões como a de Sen (2010), sobre uma inevitabilidade e até uma naturalidade do mercado acabam sendo largamente difundidas como se não existissem alternativas.

Segundo Rifkin (2004, p. 245):

O terceiro setor incorpora muito dos elementos necessários para uma contundente visão alternativa ao ethos utilitário do mercado. Ainda assim, o espírito da economia social ainda não se solidificou em uma poderosa visão de um mundo compensatório, capaz de definir uma ordem do dia para uma nação. 
Isso se deve em grande parte ao extraordinário poder que os valores do mercado têm exercido sobre os assuntos dos Estados Unidos.

A difusão do terceiro setor, a percepção de uma solução compartilhada e comunitária para problemas que, comumente, são equalizados pelo mercado, uma visão mais solidária e menos individualista, dentre outros fatores, acabam por colidir com os interesses ligados à visão da economia de mercado e da cultura do consumo. São ameaças, que tendem a ser repelidas, sobretudo quando estão em xeque paradigmas, como os da produtividade, do lucro e do consumo de massas.

Um outro rumo se torna necessário. Impõe-se a construção de uma terceria via, que

[...] permita aos trabalhadores se beneficiarem dos ganhos de produtividade, com semanas de trabalho menores e renda adequada, mais tempo livre existirá do que em qualquer outro tempo da história moderna. Esse tempo livre poderia ser usado para renovar os vínculos comunitários e rejuvenescer a herança democrática. Uma nova geração poderá transcender os limites estreitos do nacionalismo e começar a pensar e agir como membros comuns da raça humana, com compromissos compartilhados entre si, a comunidade e a biosfera maior. (RIFKIN, 2004, p. 247)

Rifkin (2004) não esconde a nota utópica e revolucionária destas ideias, sem, contudo, considerá-las um caminho impossível, pois adverte que a substituição dos homens por máquinas foi, no passado, um sonho quase utópico e fantástico, mas que veio a se concretizar em um curtíssimo espaço de tempo, o que, também, pode ocorrer com o cooperativismo e o terceiro setor.

\section{CONCLUSÃO}

Recuperando o objetivo central apresentado na introdução, buscou-se traçar um esboço de como o conceito de trabalho foi moldado, assim como destacar os desafios que já se apresentam e que, sem dúvidas, provocarão alterações significativas no mundo do trabalho.

Trata-se, portanto, de uma temática em constante movimento mas que, diferentemente do que ocorre atualmente, na academia e na sociedade como um todo, deve ser enfrentada criticamente. A metamorfose do trabalho não ocorre, nem ocorreu por inércia. Tampouco estamos fadados a aceitar, irrefletidamente, todas as transformações que se impõem. 
O passado, a recuperação dos elementos históricos que forjaram o tema, ajuda-nos a aprender com os erros, discutir e apontar caminhos que nos permitam, entre outras coisas, um reencontro do trabalho com a integração social e, principalmente, um reencontro do trabalhador consigo próprio enquanto indivíduo.

A racionalidade econômica, que movimenta o mundo do trabalho desde sua ascensão, em tempos modernos, vem dando provas de saturação. As sucessivas e cada vez mais profundas crises que assolam o mundo demonstram isso. Contudo, a resposta às crises tem sido no sentido de aprofundamento da desintegração social, do incremento do desemprego e da deterioração do papel do Estado como agente de bem-estar social.

Propor um debate dessa monta, em outros termos, discutir os efeitos deletérios do capitalismo e da globalização e seus reflexos no mundo do trabalho, não significa, como muitos tentam fazer crer, um pleito pelo comunismo ou outro discurso vazio do gênero. Significa, apenas, a necessidade de se olhar e pensar um mundo para além do capital, já que ele próprio é incapaz de equacionar suas próprias distorções e contradições.

A solução apresentada aqui, ainda que em breve linhas, sem desconsiderar outras tantas igualmente importantes, passam por um "chamamento" do indivíduo para o reencontro com seus pares, por meio de uma cooperação e integração verdadeiramente sociais. O terceiro setor pode, e deve, ser um caminho para isso através das práticas de voluntariado. Nesse campo, cada um, em igual medida, dentro de suas habilidades, já tão especializadas e subdivididas, pode fazer parte de um todo para a construção de um outro tipo de capital, com uma outra racionalidade, pautado pela ética, pela alteridade e pela solidariedade.

\section{REFERÊNCIAS}

ARENDT, H. A condição humana. 11. ed. Rio de Janeiro: Forense, 2014.

GORZ, A. Metamorfoses do trabalho: crítica da razão econômica. São Paulo: Annablume, 2003.

IANNI, O. A era do globalismo. 12. ed. Rio de Janeiro: Civilização Brasileira, 2014.

LESSA, S. História e ontologia: a questão do trabalho. Critica Marxista (Roma), CEMARX/ Unicamp, v. 20, p. 70-89, 2005. 
RIFKIN, J. O Fim do Empregos: o contínuo crescimento do desemprego em todo o mundo. São Paulo: M.Books, 2004.

SILVA, J. P. da. Trabalho, Cidadania e Reconhecimento. São Paulo: Annablume, 2008.

WACQUANT, Loic. As prisões da miséria. 2. ed. Rio de Janeiro: Zahar, 2011. 